\title{
Administrasi dan Supervisi Pendidikan
}

\author{
Universitas Negeri Padang \\ Indonesia \\ E -mail : meliasridevi@gmail.com
}

\author{
Hade Afriansyah \\ Universitas Negeri Padang \\ Indonesia \\ E-mail : hadeafriansyah@fip.unp.ac.id
}

\begin{abstract}
Abstrak-Special service administration is to provide services specifically or a business that is not directly related to the teaching and learning process in the classroom. But specifically given by the school to the students so that they are more optimal in carrying out the learning process_Special service management in schools is basically set and organized to facilitate or facilitate learning, and can meet the special needs of students at school. Special services are held in schools with the aim of facilitating the implementation of teaching in the context of achieving educational goals in schools. Education in schools also includes trying to keep students in good condition. Good here concerning physical and spiritual aspects. Special services provided by schools to students, between schools one with other schools are generally the same, but the management process and utilization are different. Some special services available at school include: Library, Labor, UKS (School of Health Business), School Kafetaria, Facilities of worship, Dormitory, Cooperatives and Transportation. Thus, special service management is a process of providing services to students to support learning activities so that educational goals can be achieved effectively and efficiently.
\end{abstract}

Keyword : administration; special services.

\section{Pendahuluan}

Pentingnya administrasi layanan khusus bagi sebuah instansi pendidikan, tentu menjadi acuan bagi pihak orang tua untuk memasukan anak-anak nya ke sekolah yang telah memenuhi standar dan juga dapat dikatakan bahwa tempat itu adalah sekolah ungulan dan menjadi incaran bagi pelamar dan menjadi acuan/rujukan oleh pihak orang tua untuk memasukan anaknya ke sekolah tersebut.

Administrasi Layanan khusus yang telah memadai dan sesuai dengan kriteria orang tua dan peserta didik tentulah harus memenuhi ekpetasi siswa yang menjadikan peserta didik merasa betah dan nyaman diekolah malah ingin terus berada di sekolah dan jika telah berada dirumah malah ingin kembali lagi sekolah karena layanan yang diberikan oleh pihak sekolah sangatlah memuaskan, seperti Perpustakaan yang dilengkapii oleh buku-buku yang sesuai dengan pelajaran bahkan bervariasi, Labor yang membuat siswa merasa senang untuk berekperime, (UKS) Unit Kesehatan Sekolah Usaha kesehatan sekolah adalah usaha kesehatan masyakarat yang dijalankan di sekolah yang membuat siswa jurusan IPA khususnya merasa nyaman dan betah, Kafetaria sekolah, Sarana ibadah, Asrama, Koperasi dan Transportasi

\section{Metode PENELITIAN}

Penelitian ini termasuk jenis penelitian yang menekankan pada pemanfaatan buku-buku, jurnal serta sumber lainnya yang terkait dengan pembahasan mengenai Administrasi layanan khusus.
Pada artikel ini, penulis menggunakan metode studi pustaka, dengan cara mengumpulkan (bahan-bahan, materi) yang bersumber dari buku, jurnal, dan sumber lainnya terkait ilmu Administrasi dan Supervisi Pendidikan yang ada di perpustakaan Nniversitas Negeri Padang. Studi pustaka merupakan metode penelitian yang sangat digemari oleh intelektual kampus termasuk oleh penulis, karena penulis dapat memanfatkan sumber yang tersedia disekitar penulis.

\section{KAJIAN TEORI DAN PEMBAHASAN}

A. Pengertian Administrasi Layanan Khusus

Sesuai dengan UU No. 19 Tahun 2005 tentang Standar Nasional Pendidikan Bab II Pasal 4 yang memuat tentang adanya tujuan pendidikan nasional. Untuk memenuhi tugas dan tanggung jawab tersebut maka sekolah memerlukan suatu manajemen layanan khusus yang dapat mengatur segala kebutuhan peserta didiknya sehingga tujuan pendidikan tersebut dapat tercapai. Manajemen layanan khusus adalah suatu proses kegiatan memberikan pelayanan kebutuhan kepada peserta didik untuk menunjang kegiatan pembelajaran agar tujuan pendidikan bisa tercapai secara efektif dan efisien.

B. Jenis-jenis layanan khusus diantaranya :

1) Perpustakaan

Dengan adanya perpustakaan yang menyediakan banyak koleksi buku, tentu membuat siswa merasa betah dan ingin berlama lama di sekolah, karena siwa yang haus akan sumber informasi, dengan buku siswa dapat membuka jendela dunia selebar-lebarnya dan dapat mengetahui berbagai hal yang belum ia ketahui seperti sejarah beradaban manusia, perjuangan rakyat Indonesia dan masih banyak lagi

\section{2) Labor}

Menurut kamus besar bahasa indonesia (kbbi) tempat atau kamar dan sebagainya tertentu yang dilengkapi dengan peralatan untuk mengadakan percobaan (penyelidikan dan sebagainya). Tentu dengan adanya labor yang memenuhi kapasitas dan kesediaan dari peralatan yang lengkap tentu menjadi daya tari yang sangat besar bagi siswa untuk terus berada di sekolah karena layanan yang diberikan sangatlah memuaskan dan dapat membuat siswa tidak jenuh dan bosan berada di sekolah, diantara labor yang harus disediakan sekolah diantaranya :
a) Labor kimia
b) Labor biologi
c) Labor agama 
d) Labor musik

e) Labor teknik

f) Dan lain sebagainya

\section{3) Unit Kesehatan Sekolah (UKS)}

Setiap siswa banyak yang bercita cita menjadi dokter, maknya setiap siswa masuk ke sekolah unggul maupun sekolah pada biasanya, kebanyakan dari mereka mencari kegiatan di luar jam pelajaran, salah satunya unit kesehatan sekolah (uks) hal itu mrusakann sesuatu yang lumrah dan biasa karena mereka para siswa lebih banyak tertarik di bidang kesehatan, yang membuat mereka memilih untuk bergabung di eksschol uks ini, sekolah memandang hal ini sesuatu yang dari tahun ke tahun merupakan sesuatu yang biasa dan tidak menjadi permasalahan, bahkan orang tua yang memiliki anaknya masuk kegiatasn uks ini merasa senang dan banga jika anaknya dapat menjadi angota di kegiatan ini, tentu pihk sekolah harus mampu menghadapi tantangan dan rintangan yang ada dilapanga,dan layana khusu ini menjadi pertimbangan juga bagi orang tua yang ingin mamasukkan anaknya di sekolah tersebut.

\section{4)Kafetaria Sekolah}

Menurut Tim Dosen Administrasi Pendidikan Universitas Pendidikan Indonesia (2011), "kantin atau warung sekolah diperlukan adanya pada tiap sekolah supaya makanan yang dibeli peserta didik terjamin kebersihannya dan cukup mengandung gizi". dari kutipan tersebut dapa dipahami bahwa sekolah yang ingin siswanya memakan makanan yang sehat dan baik haruslah memiliki kantin atau warung yang diperlukan agar apa,? Agar peserta didik dapa memakan makanan yang sehat dan dapa menjaga kesehatan dari setiap peserta didik dan juga makanan yang bergizi menjadi pertimbangan dari semua pihak agar siswa dapat sehat dan terjaga kesehatanya, hal ini juga menjadi satu pertimbngan bagi orang tua untuk memasukan buah hatinya di sekilah yang bersangkutan.

\section{5) Sarana Ibadah,}

tempat ibadah merupakan tempat yang sangat dibutuhkan oleh setiap sekolah, dengan adanya tempat ibadah yang nyaman dan memadai maka orang tua dapat dengan tenang memasukkan anaknya ke sokolah tersebut, karena sarana ibadah merupakan hall yang sangat dibutuhkan oleh setiap individu untuk melaksanakan rutinitas spiritual para siswa, pendidik dan masyarakat sekitar sekolah yang dapat memnfaatkan sarana ibadah tersebut.

\section{6) Asrama}

Menurut kbbi asrama merupakan bangunan tempat tinggal bagi kelompok orang untuk sementara waktu, terdiri atas sejumlah kamar, dan dipimpin oleh seorang kepala asrama;

Dari uraian di atas tentu dari setiap sekolah hannya ada beberapa yang mampu menyediakan fasilitas asrama yang memadai dan sesuai dengan ynag seharusnya, namun di Negara kita Indonesia sekolah banyak yang tidak memiliki asrama yang di pengaruhi oleh banyak faktorm namun walaupun asrama tidak ada bukan berarti semnagat dari para siswa kendar, mlahan semanngat dari siswa lebih besar, Karen ada dorongan dari orang tua yang membuat siswa menjadi lebih semangat dan juga iswa jug adapt terkontrol perilakunya, bukan berarti di asrama perilaku anak tidak dapat dikontrol namun itu peranan orang tua lebih memdominasi dari pada pebimbing/guru.

\section{7) Koperasi}

Suatu usaha yang dibentuk di lingkungkan sekolah, baik lembaga pendidikan formal maupun non formal, dimana anggotanya adalah para siswa di sekolah tersebut. Dari uraian diatas tentu koperasi sekolah suatu usaha yang resmi atau tidak resmi yang dapat memberdayakan warga sekolah, karena di kelola langsung oleh guru, siswa dan warga sekolah lainya yang dapat memberikan manfaat secara materil untuk pelaku koperasi.

\section{8) Dan Transportasi}

Trasnportasi merupakan hal yang sangat di perlukan oleh setiap orang tidak hanya untuk siswa para pekerjapun membutuhkan saran transportasi untuk dapat sampai ke tempat tujuan nya dengan cepat dan aman, namun setiap sekolah dapat dkatakan belum bisa menyediakan transportasi yang dapat menunjang siswanya dapat hadir di sekolah, namun hal itu tidaklah dipermasalahkan karena saran transportasi yang lain masih ada, seperti angkot, ojek dan lain sebagainya, tentu sarana transportasi yang $\mathrm{d}$ sediakan oleh pihak sekolah membuat pihak orang tua lebih berbondong-bondong memasukan anaknya kesekolah yang bersangkutan karena dapat dikatakan, sekolah yang layanan khususnya memadai makin banyak di sekai oleh siswa dan dapat dikatakan fasiltas pendidkan nya lebih berkualitas dan bermutu di mata orang tua dan guru, serta masyarakat.

\section{Peran Guru dalam Administrasi Layanan Khusus}

1. Keterlibatan guru dalam administrasi perpustakaan misalnya memperkenalkan buku-buku kepada siswa

2. Mempromosikan perpustakaan baik pemakaian maupun untuk pembinaannya.

3. Memberikan contoh yang baik untuk mengunakan tempat ibadah katakankanlah sholat wajib dan tempat untuk mengaji

4. Berpartisipasi untuk menunjukkan minta dan bakat siswa di bidang penelitian

\section{KESIMPULAN}

Administrasi layanan khusus merupakan Manajemen layanan khusus di suatu sekolah yang mejadi bagian penting dalam Manajemen Berbasis Sekolah (MBS) yang efektif dan efisien. Yang tidak hanya mebentuk intelektual namun juga spirtitual serta jasmani dan rohani yang membuat peserta didik merasa nyaman dan senang di sekolah, manajemen laynan khusu yang terdiri atas delapan jenis layanan yang seperti 1. perpustakaan, 2. labor, 3. (UKS) Unit Kesehatan Sekolah, 4. Kafetaria sekolah, 5. sarana ibadah, 6. Asrama, 7. Koperasi 
dan 8. Transportasi. Serta peran guru dalam administrasi layanan khusus

\section{Daftar Pustaka}

https://aniafitriah.wordpress.com/2016/01/26/manajemenlayanan-khusus diaploud tanggal 26/06/2019 jam 00.10 wib Tim Dosen Administrasi Pendidikan Universitas Pendidikan Indonesia. 2011. Manajemen Pendidikan. Bandung: Alfabeta. https://kbbi.web.id/asramadi aploud tangal 27/06/2019jam 10 00 wib.

file://C:/Users/Acer/Downloads/95-196-1-SM.pdf di aploud tanggal 27/06/2019 jam 0945 wib.

https://lib.unnes.ac.id/10657/1/12200.pdf di aploud tanggal 27/06/2019 jam 0950 wib. 